\title{
Assessing the Knowledge Level of Teachers of Children with Autism Spectrum Disorder about the Importance of Applied Behavior Analysis (ABA) Strategies in Zarka City
}

\author{
Yasser F. Khaleel ${ }^{1}$ \\ ${ }^{1}$ Department of Special Education, Faculty of Education, Jadara University, Jordan \\ Correspondence: Yasser F. Khaleel, Department of Special Education, Faculty of Education, Jadara University, \\ Jordan.
}

Received: December 28, 2018

Accepted: February 9, 2019

Online Published: April 29, 2019

doi:10.5539/ies.v12n5p120

URL: https://doi.org/10.5539/ies.v12n5p120

\begin{abstract}
The current study aimed at assessing the knowledge level of teachers of children with Autism Spectrum Disorder about the Importance of Applied Behavior Analysis (ABA) strategies in Zarka City. Furthermore, the study attempted to explore whether teachers' knowledge level differ according to their gender, years of experience, level of education, or specialized training. The sample of this study comprised of (60) teachers ( 25 male and 35 female). In order to achieve the goals of this study, the researcher constructed a questionnaire. The final version of it consisted of (27) items. The results showed that teachers of children with Autism Spectrum Disorder were given a high degree of importance on the whole scale. The mean was (2.95). The results also indicated no statistically significant differences in total degrees of importance of (ABA) strategies can be attributed to gender or level of education, while there were statistically significant differences in total degrees of importance of (ABA) strategies can be attributed to training. Finally, the results indicated statistically significant differences in total degrees of importance and no statistically significant differences in total degrees of use of (ABA) strategies can be attributed to years of experience.
\end{abstract}

Keywords: teachers of children with autism spectrum disorder, Applied Behavior Analysis (ABA) strategies, importance of ABA strategies, knowledge level

\section{Introduction}

In recent years, attention has been paid to the Autism Spectrum Disorder affecting children and their natural development. This concern is since early intervention and finding appropriate solutions and strategies in improving the skills of individuals with Autism Spectrum Disorder at an early age enable them to face difficult challenges. Autism Spectrum Disorder is one of the most complex developmental disorders. It has been observed in recent years a marked increase in the prevalence of Autism Spectrum Disorder, as information from the Center of Disease Control and Prevention, CDC (2009) that the prevalence of Autism Spectrum Disorder is equal to one case in every (90) children. In Saudi Arabia, King Abdul Aziz City for Science and Technology conducted a study to determine the prevalence of Autism Spectrum Disorder. The study found that the prevalence of Autism Spectrum Disorder in the Kingdom (4-6/1000) children (Jarallah, Al-Wazna, Ansari, \& Hazmi, 2006). Many children with Autism Spectrum Disorder are enrolled in various educational centers to receive educational and behavioral services. It is worth to mention that most of the programs offered to children with Autism Spectrum Disorder are based on the principles of applied behavior analysis. The most common of these programs are Functional Communication Training (FCT), Verbal Behavior Approach (VB), Discrete Trial Training (DTT), Picture Exchange Communication System (PECS), and Video Modeling. So, researchers concerned about the efficacy of these programs. From here we can see that teachers and specialists have a major role in developing the lives of people with Autism Spectrum Disorder. To provide better life opportunities for these individuals, it was necessary to train teachers and develop their skills. Teachers are considered the better persons who can diagnose challenges and identify appropriate strategies to develop their skills (Haimour \& Obaidat, 2013).

The educational literature pointed to the need to train and qualify teachers working with people with special needs in general and with individuals who suffer from Autism Spectrum Disorder in particular, and in order to enable the teacher to provide quality services and high efficiency, he must be trained to develop his skills on a continuous 
basis, which will help in growth and development of these individuals' skills. Studies have indicated - for more than 25 years - that the method of analysis of applied behavior is one of the most effective treatment methods in the modification of negative behaviors and increase positive behaviors in individuals suffering from Autism Spectrum Disorder (Wallin, 2004).

\subsection{Statement of Problem}

Teachers use different training strategies to generalize acquired skills and maintain social skills. These strategies focus on addressing the challenges and behavioral problems teachers face in dealing with individuals with special needs in general and Autism Spectrum Disorder in particular.

The strategies of applied behavior analysis are the most widely used methods of special education teachers. Hence the current study problem arises in assessing the knowledge level of teachers of children with Autism Spectrum Disorder about the Importance of applied behavior analysis (ABA) strategies in Zarka city, Jordan.

\subsection{Objectives of the Study}

The purpose of the study was to find out the level of knowledge of teachers of autistic children about strategies of applied behavior analysis in terms of importance. In addition, this study attempted to find out if there any significant differences of teachers' knowledge about strategies of applied behavior analysis in terms of importance based on their gender (female or male), experience (less than 5 years, 5-10 years, more than 10 years), level of education (bachelor's degree and below or master's degree and above) and training variables.

Specifically, this study aimed to answer the following questions:

1) Which behavioral analysis strategies are most important for teachers of autistic children?

2) Are there any significant differences of teachers' knowledge about strategies of applied behavior analysis in terms of importance based on their gender, experience, level of education and training variables?

\subsection{Significance of the Study}

The results of this study will reveal the level of teachers' knowledge about strategies of applied behavior analysis in terms of importance, which will contribute to the construction of pre and in- service training programs to improve their level and efficiency, which will positively affect students with Autism Spectrum Disorder and programs presented to them.

\subsection{Borders and Limitations of the Study}

The results of this study were determined in the academic year 2017/2018, in Zarqa, Jordan, and in the special education teachers of the private centers who deal with autistic children, and objectively to the responses of the study sample to study tool and statistical methods used.

\subsection{Procedural Definitions of Terms}

Applied Behavior Analysis Strategies:

Are the strategies used to modify the behavior which can be manifested in the total degree obtained by teachers of autistic children responses on the study tool prepared by the researcher.

Teachers of autistic children:

In this study, teachers of autistic children are the special education teachers who deal with autistic children in private centers in Zarqa, Jordan.

\section{Theoretical Background and Literature Review}

The Autism Spectrum Disorder is one of the most complex developmental disorders that occur during the first three years of a child's life. Autism Society of America (ASA) defines Autism Spectrum Disorder as a type of severe developmental disorder that occurs during the first three years of a child's life and interferes with the natural development of the brain in areas that control verbal and nonverbal communication, social interaction, and sensory development (Bogdashina, 2006).

Autism Spectrum Disorder is a confusing and controversial disorder due to the complexity of its manifestations, its different characteristics and its interplay with many other disorders. This has led to difficulties in determining its causes so far. There are many theories that trying to explain it, including: genetic theory, psychological theory, viruses and infectious diseases, the theory of mind, the theory of factors before, during, and after birth, and the theory of vaccines (Bogdashina, 2006; Liedel, 2008).

In the study of the nature of children with Autism Spectrum Disorder, we find that they are a heterogeneous group 
of characteristics, but most of them are similar in general characteristics, which are summarized in the following: Social characteristics: They have difficulty in visual communication and social relations, and difficulty in expressing emotions and feelings and understanding others' feelings (Bogdashina, 2006; Buckendorf, 2008). In terms of communicative characteristics, they show a marked delay in the development of language, or lack of speech development, and the emergence of stereotypical forms of speech such as repetition, monotonous speech, failure to understand spoken and unspoken language, poor conversational skills (Bogdashina, 2006; Buckendorf, 2008). According to interests, behavior and activities, children with Autism Spectrum Disorder show limited and abnormal interests, stereotypical behaviors, attachment to specific objects, and routine behaviors. Finally, in the field of sensory characteristics, some children with Autism Spectrum Disorder show high or low sensory (auditory, visual, olfactory, or tactile) responses (Shami, 2004, Smadi, 2007).

Increasing legislative demands placing an emphasis on teacher qualities raise questions about teachers who work with students with Autism Spectrum Disorder. As a result, it has become increasingly necessary to ensure school teachers are adequately prepared and possess requisite knowledge and skills (Haimour \& Obaidat, 2013).

Referring to early intensive behavioral intervention programs, they consist of the application of principles of applied behavior analysis (Granpeesheh, Tarbox, \& Dixon, 2009; Fong \& Aldalalah, 2010). Applied behavior analysis is a behavioral modification approach, defined by Prior (2003) as the systematic application of behavioral principles to address deficits in social behavior, verbal skills, and thinking skills. Applied behavior analysis describes human behavior in observable measurements.

Applied behavior analysis strategies include strategies to increase desired behavior such as reinforcement, and strategies to reduce unwanted behavior such as punishment, extinction, cost of response, exclusion and over-correction, and strategies to maintain desired behavior such as fixed ratios, variable ratios, and strategies to build a new behavior such as forming behavior, and consolidation, and data recording strategies as repetition and the duration of the behavior occurs, and time intervals (Jaffe, 2010).

The following is a brief review of the studies relevant to the subject of the current study that the researcher can obtain, although the researcher has had difficulty in obtaining studies directly related to the current study.

Al-Khatib (1993) examined the goal of knowing the teachers of the mentally disabled in behavioral modification strategies and their relation to some variables related to teaching experience and scientific qualifications. The study sample included (74) teachers working with children with mental disabilities. The results showed that there were no statistically significant differences in the level of this knowledge due to any teaching experience or scientific qualification.

Whaley (2002) also conducted a study aimed at examining the level of knowledge of special education teachers and speech - language pathologists in North Tennessee schools with educational programs and the causes of Autism Spectrum Disorder. The study focused on identifying effective methods used by teachers and comparing them with the latest techniques and training methods. The sample included (192) teachers and specialists who were asked to answer a test consisting of Yes or No questions and multiple-choice questions. Where the results of the study indicate a weakness in the level of knowledge of the sample of the modern methods in dealing with Autism Spectrum Disorder in general, which requires re-training.

Lerman, Vorndran, Addison, and Kuhn (2004) conducted a study on teacher training in how to deal with autistic individuals. The study questioned teachers' ability to learn multiple strategies at a specific time and acquire specific skills more quickly than other skills. The study showed a preference for the use of specific promotion strategies on other strategies. The results of the study showed that teachers have applied less than $65 \%$ of the strategies correctly, which requires re-training and better rehabilitation.

Cascella and Colella (2004) conducted a study aimed at assessing the level of knowledge of language and speech therapists in the Autism Spectrum Disorder. The study sample consisted of 182 specialists at the Connecticut School. The results of the study showed that $54 \%$ results of the study indicate that specialists need special training on educational and behavioral intervention strategies such as behavioral analysis strategies and sensory integration. The rest of the sample confirmed their knowledge of coping strategies for autistic children as a result of training, but they need continuous training on new techniques and strategies.

Al-Khatib (2005) conducted a study aimed at examining the effectiveness of a collective training program in improving the level of knowledge of teachers of mentally disabled children with the principles of behavioral modification and methods. The sample included 41 teachers working in centers and institutes of special education in the GCC countries. The results of the study showed that the training program was effective in increasing the level of knowledge of teachers and the principles of the behavior modification, and the results indicated that there 
are differences of statistical significance attributed to scientific qualifications, while there were no differences of statistical significance due to gender or experience.

Grey, Honan, Mclean, and Daly (2005) examined the effectiveness of the training of eleven teachers of autistic children on the principles of applied behavior analysis. The results showed that teachers were able to record data of targeted behavior and baseline design and others. The results of the study indicated that there were significant differences in the performance of teachers before and after training.

In a study by Al-Hiari (2006), the aim was to examine the level of importance and use of autistic children's parents and teachers of behavioral analysis strategies. The study sample consisted of 38 parents and 49 children with Autism Spectrum Disorder in Texas and California. The results of the study showed that parents and teachers used the most important strategies for them. Parents gave a high degree of importance to the modeling strategy, while the teachers showed a high degree of importance and use of the modeling strategy, and the results of the study showed that there are statistically significant differences in the importance and use of behavioral analysis strategies by parents and teachers according to the study variables.

Orabi (2007) conducted a study aimed at assessing the level of knowledge of the teachers of autistic children in the Syrian Arab Republic with behavioral modification methods. The study sample consisted of 72 teachers. The results of the study indicated that the average score of these teachers on the scale as a whole was close to the normative value determined by the jury, which represents the minimum knowledge of behavioral modification methods. The results also showed significant differences in teachers' knowledge of behavioral modification methods due to gender variable. The results showed that there were statistically significant differences between male \& female teachers on the general knowledge of the general principles of behavior modification and knowledge of ways to weaken undesirable behavior in favor of male teachers. The results also showed statistically significant differences in teachers' knowledge of behavioral modification methods attributed to the academic qualification in favor of the holders of the postgraduate degree. As for the variable of experience, the results indicated that there are statistically significant differences in knowledge of behavioral modification methods due to experience for less experienced teachers in the field of Autism Spectrum Disorder.

\section{Design and Methodology}

\subsection{Research Design}

In this study, the researcher used descriptive analytical method to measure the knowledge level of teachers of autistic children about strategies of applied behavior analysis in terms of importance in Zarqa city where the researcher distributed the tool to the study sample to obtain the required data in the study.

\subsection{The Population of Sample}

The current study population consisted of all the special education teachers who deal with autistic children in private centers in Zarqa, Jordan for the academic year 2017/2018, estimated to be 120 teachers.

The study was conducted on a sample of special education teachers who work with Autism Spectrum Disorder in the private centers in Zarqa, Jordan. The number of teachers was 60 teachers, 25 male teachers and 35 female teachers. Table 1 demonstrated the distribution of the study sample according to gender, educational level, experience, and training variables.

Table 1. Study sample distribution according to the variables of the study

\begin{tabular}{cccc}
\hline \multicolumn{2}{c}{ Study Variables } & Number & Percentage (\%) \\
\hline \multirow{2}{*}{ Gender } & Male & 25 & 41.7 \\
& Female & 35 & 58.3 \\
Educational Level & Diploma or less & 10 & 16.7 \\
& Bachelor or above & 50 & 83.3 \\
\multirow{4}{*}{ Experience } & 1-5 years & 17 & 28.3 \\
& 6-10 years & 14 & 23.3 \\
\multirow{4}{*}{ Training } & More than 10 years & 29 & 48.3 \\
& Yes & 27 & 45.0 \\
& No & 33 & 55.0 \\
& Total & 60 & 100.0 \\
\hline
\end{tabular}




\subsection{Study Tool}

To achieve the goal of the study which is to find out the knowledge level of teachers of autistic children about strategies of applied behavior analysis in terms of importance in Zarqa city, the researcher built a survey tool consisting of two parts, the first part includes demographic information: gender, educational level, and years of experience in teaching the individuals with Autism Spectrum Disorder, and training in strategies for the applied behavior analysis, while the second part of the tool included a questionnaire consisting of 27 paragraph using the Likert ladder, and the researcher put five options for importance ranging from 0 to 4 , the score (0) indicates that the paragraph is not important, and class (4) that the paragraph is very important.

\subsection{Tool Validation}

To verify the validity of the tool, the researcher presented it to ten arbitrators who are specialized in special education at Jordan University, Irbid National University, Jadara University and King Abdul Aziz University in Saudi Arabia. They were asked to express their opinion on the clauses of the tool in terms of correctness of the phrases, their clarity and safety in terms of meaning and wording. All the observations of the arbitrators were put into consideration. They included some limited language modifications, replacing some vocabulary with another, and shortening some clauses. Arbitrators noted that the tool is suitable to detect the knowledge level of teachers of autistic children about strategies of applied behavior analysis in terms of importance from the point of view of teachers of autistic children in Zarqa city.

\subsection{Tool Stability}

To confirm the stability of the tool, the coefficients of internal consistency were calculated using the Cronbach alpha formula to determine the degree of stability of the instrument on the degree of importance of strategies of applied behavior analysis as shown in Table 2 .

Table 2. Stability coefficients in the Cronbach Alpha method

\begin{tabular}{lc}
\hline & Degree of stability coefficient (Cronbach alpha) \\
\hline Importance & 0.82 \\
\hline
\end{tabular}

\section{Results}

For the purpose of determining the importance and use, the scale of the answer ranged between (0-4) degrees, indicating the degree (0) to the degree of low importance, the grade (4) indicating the high importance, $(0-1.33)$ low degree of importance, (1.34-2.66) medium degree of importance, (2.67-4) high degree of importance.

The following are the answers to the study questions:

Question 1: Which strategies of applied behavior analysis are more important for teachers and teachers of individuals with Autism Spectrum Disorder?

To answer these questions, the arithmetical averages and the standard deviations of the degrees of importance of applied behavioral analysis strategies were extracted and their rank was extracted. 
Table 3. Arithmetical averages and standard deviations of degrees of importance of applied behavior analysis strategies

\begin{tabular}{|c|c|c|c|}
\hline \multirow{2}{*}{ Strategies } & \multicolumn{2}{|r|}{ Importance } & \multirow{2}{*}{ Ordering the strategy importance } \\
\hline & Mean & Standard Deviation & \\
\hline 12. Modeling & 3.73 & 0.58 & 1 \\
\hline 4. Social Reinforcers & 3.73 & 0.52 & 2 \\
\hline 7. Indoctrination & 3.50 & 0.72 & 3 \\
\hline 2. Natural reinforcers & 3.42 & 0.70 & 4 \\
\hline 8. Concealment & 3.42 & 0.74 & 5 \\
\hline 1. Food reinforcers & 3.38 & 0.76 & 6 \\
\hline 9. Formation & 3.18 & 0.79 & 7 \\
\hline 27. Recording intervals & 3.15 & 0.99 & 8 \\
\hline 25. Recording Frequency of Behavior & 3.10 & 0.97 & 9 \\
\hline 18. Extra Correction & 3.02 & 1.05 & 10 \\
\hline 10. Extinction & 2.95 & 0.89 & 11 \\
\hline 11. Sequence & 2.95 & 0.91 & 12 \\
\hline 21. Variable Ratio Reinforcement Schedule & 2.93 & 0.92 & 13 \\
\hline 6. Negative reinforcement & 2.90 & 1.10 & 14 \\
\hline 24. Continuous Measurement & 2.90 & 1.04 & 15 \\
\hline 16. The cost of the response & 2.85 & 1.02 & 16 \\
\hline 26. Recording the duration of the behavior & 2.85 & 1.02 & 17 \\
\hline 19. Punishment & 2.82 & 1.13 & 18 \\
\hline 3. Activity reinforcers & 2.77 & 0.83 & 19 \\
\hline 14. Differential reinforcement of opposite behavior & 2.75 & 0.91 & 20 \\
\hline 20. Fixed Ratio Reinforcement Schedule & 2.72 & 1.08 & 21 \\
\hline 13. Differential reinforcement of other behaviors & 2.63 & 0.86 & 22 \\
\hline 5. Token reinforcers & 2.52 & 1.03 & 23 \\
\hline 17. Exclusion & 2.48 & 0.95 & 24 \\
\hline 23. Variable Interval Reinforcement Schedule & 2.45 & 1.05 & 25 \\
\hline 22. Fixed Interval Reinforcement Schedule & 2.27 & 1.07 & 26 \\
\hline 15. Differential reinforcement of absence behavior & 2.25 & 1.00 & 27 \\
\hline Overall score & 2.95 & 0.38 & \\
\hline
\end{tabular}

Table 3 shows that the average importance of strategies ranged between 2.25 and 3.73. The mean of the strategies of applied behavior analysis in general (2.95) was high. The highest mean of the importance was for the Modeling strategy (3.73). Finally, the importance of the Differential reinforcement of absence behavior was reached with an average of (2.25) a medium degree.

Question 2: Are there any significant differences of teachers' knowledge about strategies of applied behavior analysis in terms of importance based on their gender, experience, level of education and training variables?

The T-test was used to examine the differences in the degree of importance of the strategies and their degrees of use according to the gender of teachers. Table 4 shows the results. 
Table 4. T-Test results to examine the differences in the importance of ABA strategies according to gender

\begin{tabular}{|c|c|c|c|c|c|c|}
\hline \multirow{2}{*}{ Strategies } & \multicolumn{2}{|r|}{ Male } & \multicolumn{2}{|r|}{ Female } & \multirow{2}{*}{$\begin{array}{c}\mathrm{t} \text {-test } \\
(\mathrm{df}=58)\end{array}$} & \multirow{2}{*}{ Sig. } \\
\hline & Mean & Standard Deviation & Mean & Standard Deviation & & \\
\hline 1. Food reinforcers & 3.56 & 0.58 & 3.26 & 0.85 & 1.54 & 0.130 \\
\hline 2. Natural reinforcers & 3.32 & 0.75 & 3.49 & 0.66 & -0.91 & 0.368 \\
\hline 3. Activity reinforcers & 2.88 & 0.78 & 2.69 & 0.87 & 0.89 & 0.376 \\
\hline 4. Social Reinforcers & 3.68 & 0.56 & 3.77 & 0.49 & -0.67 & 0.504 \\
\hline 5.Token reinforcers & 2.60 & 0.91 & 2.46 & 1.12 & 0.52 & 0.602 \\
\hline 6. Negative reinforcement & 2.64 & 0.99 & 3.09 & 1.15 & -1.57 & 0.123 \\
\hline 7. Indoctrination & 3.56 & 0.58 & 3.46 & 0.82 & 0.54 & 0.592 \\
\hline 8. Concealment & 3.32 & 0.80 & 3.49 & 0.70 & -0.85 & 0.399 \\
\hline 9. Formation & 2.72 & 0.61 & 3.51 & 0.74 & -4.38 & 0.000 \\
\hline 10. Extinction & 2.76 & 0.72 & 3.09 & 0.98 & -1.41 & 0.165 \\
\hline 11. Sequence & 2.40 & 0.82 & 3.34 & 0.76 & -4.58 & 0.000 \\
\hline 12. Modeling & 3.96 & 0.20 & 3.57 & 0.70 & 2.70 & 0.009 \\
\hline 13.Differential reinforcement of other behaviors & 2.44 & 0.71 & 2.77 & 0.94 & -1.48 & 0.144 \\
\hline 14. Differential reinforcement of opposite behavior & 2.72 & 1.06 & 2.77 & 0.81 & -0.21 & 0.832 \\
\hline 15.Differential reinforcement of absence behavior & 2.24 & 1.09 & 2.26 & 0.95 & -0.06 & 0.949 \\
\hline 16. The cost of the response & 2.72 & 1.06 & 2.94 & 1.00 & -0.83 & 0.410 \\
\hline 17. Exclusion & 2.56 & 0.92 & 2.43 & 0.98 & 0.53 & 0.601 \\
\hline 18. Extra Correction & 3.04 & 0.89 & 3.00 & 1.16 & 0.14 & 0.886 \\
\hline 19. Punishment & 3.48 & 0.92 & 2.34 & 1.03 & 4.41 & 0.000 \\
\hline 20. Fixed Ratio Reinforcement Schedule & 2.92 & 0.64 & 2.57 & 1.29 & 1.24 & 0.219 \\
\hline 21. Variable Ratio Reinforcement Schedule & 2.80 & 0.82 & 3.03 & 0.98 & -0.95 & 0.346 \\
\hline 22.Fixed Interval Reinforcement Schedule & 2.16 & 0.99 & 2.34 & 1.14 & -0.65 & 0.519 \\
\hline 23.Variable Interval Reinforcement Schedule & 2.24 & 0.97 & 2.60 & 1.09 & -1.32 & 0.192 \\
\hline 24. Continuous Measurement & 2.72 & 1.02 & 3.03 & 1.04 & -1.14 & 0.259 \\
\hline 25. Recording Frequency of Behavior & 2.68 & 1.14 & 3.40 & 0.69 & -3.03 & 0.004 \\
\hline 26. Recording the duration of the behavior & 2.64 & 1.19 & 3.00 & 0.87 & -1.35 & 0.181 \\
\hline 27. Recording intervals & 3.04 & 1.24 & 3.23 & 0.77 & -0.73 & 0.471 \\
\hline Overall score & 2.88 & 0.45 & 3.00 & 0.33 & -1.15 & 0.255 \\
\hline
\end{tabular}

Table 4 shows that there are no statistically significant differences in the overall degree of importance of the applied behavior analysis strategies due to gender variable, which was (-1.15), the male mean was (2.88) and the females (3.00). The table also showed statistically significant differences in the mean importance of the following strategies between males and females: the Recording Frequency of Behavior strategy was (-3.03) for females, Modeling strategy was (2.7) for males, Punishment strategy was (4.41) for males, Formation strategy was (4.38)for females and the Sequencing strategy was (4.58) for females, while for other strategies, the results showed that there were no differences in the mean rates between males and females.

The analysis of the single variance was used to examine differences in the degree of importance of the strategies according to the teacher's experience. Table 5 shows the arithmetical averages, the standard deviations and the results of the analysis of the single variance. 
Table 5. Arithmetical averages, the standard deviations and the results of the analysis of the single variance of the differences in degrees of importance of strategies for the analysis of applied behavior according to years of experience

\begin{tabular}{|c|c|c|c|c|c|c|c|c|}
\hline \multirow[b]{2}{*}{ Strategies } & \multicolumn{2}{|c|}{$1-5$ years } & \multicolumn{2}{|c|}{$6-10$ years } & \multicolumn{2}{|c|}{ More than 10 years } & \multirow{2}{*}{$\begin{array}{c}\text { Calculate } \\
\text { F } \\
(\mathrm{df}=57.2)\end{array}$} & \multirow[b]{2}{*}{ Sig. } \\
\hline & Mean & $\begin{array}{c}\text { Standard } \\
\text { Deviation }\end{array}$ & Mean & $\begin{array}{c}\text { Standard } \\
\text { Deviation }\end{array}$ & Mean & $\begin{array}{l}\text { Standard } \\
\text { Deviation }\end{array}$ & & \\
\hline 1. Food reinforcers & 3.29 & 0.77 & 3.64 & 0.74 & 3.31 & 0.76 & 1.07 & 0.351 \\
\hline 2. Natural reinforcers & 3.53 & 0.62 & 3.43 & 0.76 & 3.34 & 0.72 & 0.37 & 0.691 \\
\hline 3. Activity reinforcers & 2.65 & 0.79 & 2.79 & 0.58 & 2.83 & 0.97 & 0.25 & 0.779 \\
\hline 4. Social Reinforcers & 3.71 & 0.69 & 3.79 & 0.43 & 3.72 & 0.45 & 0.10 & 0.907 \\
\hline 5.Token reinforcers & 2.41 & 1.00 & 2.14 & 1.03 & 2.76 & 1.02 & 1.85 & 0.166 \\
\hline 6. Negative reinforcement & 3.00 & 1.12 & 2.00 & 1.04 & 3.28 & 0.88 & 7.97 & 0.001 \\
\hline 7. Indoctrination & 3.47 & 0.72 & 3.50 & 1.02 & 3.52 & 0.57 & 0.02 & 0.979 \\
\hline 8. Concealment & 3.29 & 0.59 & 3.07 & 1.00 & 3.66 & 0.61 & 3.51 & 0.036 \\
\hline 9. Formation & 3.35 & 0.86 & 2.71 & 0.73 & 3.31 & 0.71 & 3.49 & 0.037 \\
\hline 10. Extinction & 3.47 & 0.62 & 2.64 & 0.74 & 2.79 & 0.98 & 4.71 & 0.013 \\
\hline 11. Sequence & 3.06 & 0.75 & 2.57 & 1.22 & 3.07 & 0.80 & 1.61 & 0.208 \\
\hline 12. Modeling & 3.76 & 0.66 & 3.71 & 0.61 & 3.72 & 0.53 & 0.04 & 0.966 \\
\hline 13.Differential reinforcement of other behaviors & 2.82 & 0.95 & 2.21 & 0.89 & 2.72 & 0.75 & 2.32 & 0.107 \\
\hline 14. Differential reinforcement of opposite behavior & 2.24 & 0.83 & 2.71 & 0.99 & 3.07 & 0.80 & 5.10 & 0.009 \\
\hline 15.Differential reinforcement of absence behavior & 1.94 & 1.03 & 1.86 & 1.03 & 2.62 & 0.86 & 4.30 & 0.018 \\
\hline 16. The cost of the response & 2.29 & 0.99 & 2.79 & 1.19 & 3.21 & 0.82 & 4.87 & 0.011 \\
\hline 17. Exclusion & 2.29 & 1.21 & 2.79 & 0.70 & 2.45 & 0.87 & 1.07 & 0.348 \\
\hline 18. Extra Correction & 2.24 & 1.09 & 3.21 & 0.80 & 3.38 & 0.90 & 8.36 & 0.001 \\
\hline 19. Punishment & 2.76 & 1.03 & 3.50 & 0.85 & 2.52 & 1.18 & 3.98 & 0.024 \\
\hline 20. Fixed Ratio Reinforcement Schedule & 2.76 & 1.15 & 2.86 & 0.66 & 2.62 & 1.21 & 0.25 & 0.783 \\
\hline 21. Variable Ratio Reinforcement Schedule & 3.00 & 0.87 & 2.43 & 0.51 & 3.14 & 1.03 & 3.08 & 0.053 \\
\hline 22.Fixed Interval Reinforcement Schedule & 2.29 & 1.16 & 2.07 & 0.83 & 2.34 & 1.14 & 0.31 & 0.736 \\
\hline 23. Variable Interval Reinforcement Schedule & 2.18 & 1.07 & 2.29 & 1.07 & 2.69 & 1.00 & 1.54 & 0.224 \\
\hline 24. Continuous Measurement & 2.76 & 1.03 & 2.43 & 1.22 & 3.21 & 0.86 & 3.06 & 0.054 \\
\hline 25. Recording Frequency of Behavior & 2.94 & 0.83 & 2.71 & 1.38 & 3.38 & 0.73 & 2.69 & 0.077 \\
\hline 26. Recording the duration of the behavior & 2.88 & 0.86 & 2.14 & 1.35 & 3.17 & 0.76 & 5.54 & 0.006 \\
\hline 27. Recording intervals & 2.82 & 0.88 & 2.79 & 1.53 & 3.52 & 0.51 & 4.32 & 0.018 \\
\hline Overall score & 2.86 & 0.28 & 2.77 & 0.46 & 3.09 & 0.36 & 4.26 & 0.019 \\
\hline
\end{tabular}

Table 5 shows statistically significant differences in the degree of importance of the applied behavior analysis strategies due to the teacher's experience. The value of (4.26), the mean of the experienced teachers 1-5 years was (2.86), and the experienced teachers 6-10 years (2.77), and for teachers with more than 10 years' experience (3.09). Tukey test results had shown that this difference has emerged between experienced teachers 6-10 years and experienced teachers over 10 years. The results showed that there were statistically significant differences in the importance of the following strategies due to the teacher's experience: Negative reinforcement strategy (7.97). The results of Tukey test showed that this difference was seen among experienced teachers from 6-10 years and teachers with experience of 1-5 years and teachers with experience of 10 years and more on the other hand, and the strategy of concealment, the value of (3.51). The results of the Tukey test showed that this difference has appeared between teachers experienced 6-10 years and teachers with more than 10 years of experience and a formation strategy, the value of (3.49) Tukey test has been demonstrated that this difference has emerged between experienced teachers 6-10 years and teachers with more than 10 years' experience, and extinction strategy, the value of (4.71), and the results of the Tukey test showed that this difference has emerged between experienced teachers from 1-5 years on the one hand and between teachers with 6-10 years of experience and teachers with 10 years of experience and more, and the differential reinforcement strategy of opposite behavior, the value of (5.1). The results of the Tukey test showed that this difference appeared between experienced teachers 1-5 years and teachers with more than 10 years' experience, and differential reinforcement of absence behavior strategy. The results of the Tukey test showed that this difference was seen between experienced teachers 6-10 years and teachers with more than 10 years of experience, and the cost of the response (4.87). The results of the Tukey test showed that this difference was seen between experienced teachers 1-5 years and teachers with more than 10 years 
of experience, and an Extra Correction strategy (8.36). The Tukey test results showed that this difference appeared between experienced teachers of 1-5 years on one hand and between teachers with 6-10 years' experience and teachers with 10 years' experience and more from the other side. The results of the Tukey test showed that this difference was seen between experienced teachers 6-10 years and teachers with more than 10 years of experience, and the strategy of recording the duration of behavior (5.54). The results of the Tukey test showed that this difference was seen between experienced teachers 6-10 years and teachers with more than 10 years of experience, and a recording intervals strategy of (4.32). This difference has emerged between experienced teachers 1-5 years and experienced teachers over 10 years.

The T-test was used to examine the differences in the degree of importance of the strategies and their degrees of use according to the teacher's educational level. Table 6 shows the results.

Table 6. T-Test results to examine the differences in the importance of ABA strategies according to educational level of the teacher

\begin{tabular}{|c|c|c|c|c|c|c|}
\hline \multirow{2}{*}{ Strategies } & \multicolumn{2}{|c|}{ Diploma or less } & \multicolumn{2}{|c|}{ Bachelor or higher } & \multirow{2}{*}{$\begin{array}{c}\mathrm{t} \text {-test } \\
(\mathrm{df}=58)\end{array}$} & \multirow{2}{*}{ Sig. } \\
\hline & Mean & Standard Deviation & Mean & Standard Deviation & & \\
\hline 1. Food reinforcers & 3.40 & 0.70 & 3.38 & 0.78 & 0.08 & 0.940 \\
\hline 2. Natural reinforcers & 3.40 & 0.70 & 3.42 & 0.70 & -0.08 & 0.935 \\
\hline 3. Activity reinforcers & 2.70 & 1.16 & 2.78 & 0.76 & -0.28 & 0.784 \\
\hline 4. Social Reinforcers & 3.50 & 0.53 & 3.78 & 0.51 & -1.59 & 0.118 \\
\hline 5.Token reinforcemers & 3.00 & 0.67 & 2.42 & 1.07 & 1.64 & 0.106 \\
\hline 6. Negative reinforcement & 3.30 & 0.82 & 2.82 & 1.14 & 1.27 & 0.211 \\
\hline 7. Indoctrination & 3.40 & 0.52 & 3.52 & 0.76 & -0.47 & 0.637 \\
\hline 8. Concealment & 3.50 & 0.85 & 3.40 & 0.73 & 0.39 & 0.701 \\
\hline 9. Formation & 3.40 & 0.52 & 3.14 & 0.83 & 0.95 & 0.347 \\
\hline 10. Extinction & 3.20 & 0.63 & 2.90 & 0.93 & 0.97 & 0.335 \\
\hline 11. Sequence & 2.80 & 0.63 & 2.98 & 0.96 & -0.57 & 0.572 \\
\hline 12. Modeling & 3.80 & 0.42 & 3.72 & 0.61 & 0.40 & 0.693 \\
\hline 13.Differential reinforcement of other behaviors & 2.80 & 0.42 & 2.60 & 0.93 & 0.67 & 0.508 \\
\hline 14. Differential reinforcement of opposite behavior & 2.60 & 0.70 & 2.78 & 0.95 & -0.57 & 0.574 \\
\hline 15.Differential reinforcement of absence behavior & 2.70 & 0.95 & 2.16 & 1.00 & 1.57 & 0.121 \\
\hline 16. The cost of the response & 2.80 & 0.92 & 2.86 & 1.05 & -0.17 & 0.867 \\
\hline 17. Exclusion & 2.50 & 0.71 & 2.48 & 0.99 & 0.06 & 0.952 \\
\hline 18. Extra Correction & 2.90 & 0.74 & 3.04 & 1.11 & -0.38 & 0.704 \\
\hline 19. Punishment & 3.10 & 1.37 & 2.76 & 1.08 & 0.87 & 0.389 \\
\hline 20. Fixed Ratio Reinforcement Schedule & 3.00 & 0.67 & 2.66 & 1.14 & 0.91 & 0.366 \\
\hline 21. Variable Ratio Reinforcement Schedule & 3.10 & 0.74 & 2.90 & 0.95 & 0.63 & 0.534 \\
\hline 22.Fixed Interval Reinforcement Schedule & 2.70 & 0.67 & 2.18 & 1.12 & 1.41 & 0.163 \\
\hline 23.Variable Interval Reinforcement Schedule & 2.50 & 0.85 & 2.44 & 1.09 & 0.16 & 0.870 \\
\hline 24. Continuous Measurement & 3.10 & 0.99 & 2.86 & 1.05 & 0.67 & 0.509 \\
\hline 25. Recording Frequency of Behavior & 3.00 & 1.05 & 3.12 & 0.96 & -0.35 & 0.724 \\
\hline 26. Recording the duration of the behavior & 3.10 & 0.99 & 2.80 & 1.03 & 0.85 & 0.401 \\
\hline 27. Recording intervals & 3.10 & 0.57 & 3.16 & 1.06 & -0.17 & 0.863 \\
\hline Overall score & 3.05 & 0.37 & 2.93 & 0.39 & 0.93 & 0.357 \\
\hline
\end{tabular}

Table 6 shows that there are no statistically significant differences in the overall degree of importance of the applied behavioral analysis strategies due to the educational level of the teacher. The value was $(0.93)$. The average of the teachers' percentage of the diploma holders or less was (3.05), bachelor's degree or higher was (2.93).

The T-test was used to examine the differences in the degree of importance of the strategies and their degrees of use according to teachers' training. Table 7 shows the results. 
Table 7. T-Test results to examine the differences in the importance of ABA strategies according to teachers' training

\begin{tabular}{|c|c|c|c|c|c|c|}
\hline \multirow{2}{*}{ Strategies } & \multicolumn{2}{|r|}{ Trained } & \multicolumn{2}{|r|}{ Untrained } & \multirow{2}{*}{$\begin{array}{c}\text { t-test } \\
(\mathrm{df}=58)\end{array}$} & \multirow{2}{*}{ Sig. } \\
\hline & Mean & Standard Deviation & Mean & Standard Deviation & & \\
\hline 1. Food reinforcers & 3.26 & 0.76 & 3.48 & 0.76 & -1.15 & 0.257 \\
\hline 2. Natural reinforcers & 3.48 & 0.75 & 3.36 & 0.65 & 0.65 & 0.519 \\
\hline 3. Activity reinforcers & 2.96 & 0.71 & 2.61 & 0.90 & 1.68 & 0.098 \\
\hline 4. Social Reinforcers & 3.74 & 0.45 & 3.73 & 0.57 & 0.10 & 0.921 \\
\hline 5.Token reinforcemers & 2.59 & 1.12 & 2.45 & 0.97 & 0.51 & 0.611 \\
\hline 6. Negative reinforcement & 2.93 & 1.07 & 2.88 & 1.14 & 0.16 & 0.870 \\
\hline 7. Indoctrination & 3.37 & 0.88 & 3.61 & 0.56 & -1.26 & 0.213 \\
\hline 8. Concealment & 3.30 & 0.91 & 3.52 & 0.57 & -1.14 & 0.260 \\
\hline 9. Formation & 3.26 & 0.81 & 3.12 & 0.78 & 0.67 & 0.506 \\
\hline 10. Extinction & 2.74 & 0.98 & 3.12 & 0.78 & -1.67 & 0.100 \\
\hline 11. Sequence & 3.26 & 1.02 & 2.70 & 0.73 & 2.48 & 0.016 \\
\hline 12. Modeling & 3.78 & 0.58 & 3.70 & 0.59 & 0.54 & 0.595 \\
\hline 13.Differential reinforcement of other behaviors & 2.52 & 0.98 & 2.73 & 0.76 & -0.93 & 0.356 \\
\hline 14. Differential reinforcement of opposite behavior & 3.48 & 0.58 & 2.15 & 0.67 & 8.14 & 0.000 \\
\hline 15.Differential reinforcement of absence behavior & 2.52 & 0.89 & 2.03 & 1.05 & 1.92 & 0.060 \\
\hline 16. The cost of the response & 3.67 & 0.48 & 2.18 & 0.85 & 8.10 & 0.000 \\
\hline 17. Exclusion & 2.63 & 0.84 & 2.36 & 1.03 & 1.08 & 0.283 \\
\hline 18. Extra Correction & 3.78 & 0.85 & 2.39 & 0.75 & 6.72 & 0.000 \\
\hline 19. Punishment & 2.41 & 1.15 & 3.15 & 1.00 & -2.67 & 0.010 \\
\hline 20. Fixed Ratio Reinforcement Schedule & 2.33 & 1.30 & 3.03 & 0.73 & -2.62 & 0.011 \\
\hline 21. Variable Ratio Reinforcement Schedule & 2.74 & 1.02 & 3.09 & 0.80 & -1.48 & 0.143 \\
\hline 22.Fixed Interval Reinforcement Schedule & 2.15 & 1.26 & 2.36 & 0.90 & -0.77 & 0.443 \\
\hline 23.Variable Interval Reinforcement Schedule & 2.63 & 1.11 & 2.30 & 0.98 & 1.21 & 0.233 \\
\hline 24. Continuous Measurement & 3.00 & 1.00 & 2.82 & 1.07 & 0.67 & 0.504 \\
\hline 25. Recording Frequency of Behavior & 3.70 & 0.61 & 2.61 & 0.93 & 5.26 & 0.000 \\
\hline 26. Recording the duration of the behavior & 2.96 & 0.76 & 2.76 & 1.20 & 0.77 & 0.443 \\
\hline 27. Recording intervals & 3.81 & 0.40 & 2.61 & 1.00 & 5.92 & 0.000 \\
\hline Overall score & 3.07 & 0.37 & 2.85 & 0.37 & 2.37 & 0.021 \\
\hline
\end{tabular}

Table 7 shows that there are statistically significant differences in the overall degree of the importance of the applied behavior analysis strategies among the teachers who attended training courses and the teachers who did not attend training courses, the value of (2.37). For teachers who received training it was (3.07) and for teachers who did not receive training it was (2.85). The results showed that there were statistically significant differences in the mean of the following strategies among the teachers who received the training courses and the teachers who did not receive the training courses: the sequencing strategy (2.48) for the teachers who received training, the differential reinforcement strategy for the opposite behavior (8.14) for teachers who received training, the cost of response strategy (8.1) for teachers who received training and the extra-correction (6.72)for teachers who received training, punishment (2.67) for teachers who did not receive training and the strategy of the Fixed Ratio Reinforcement Schedule was (2.62-)for teachers who did not receive training, and the strategy for Recording Frequency of Behavior the value was (5.26) for teachers who received training, and a Recording intervals strategy, it was (5.92) for teachers who received training.

\section{Discussion of Results}

The present study aimed to identify the knowledge level of teachers of children with Autism Spectrum Disorder about the Importance of applied behavior analysis (ABA) strategies in Zarka city, Jordan. The study also examined whether teachers' knowledge level differ according to their gender, years of experiences, level of education, or specialized training.

The results of the study showed that the mean of the strategies of applied behavior analysis in general was high (2.95). The highest mean of the importance was for the Modeling strategy (3.73), the importance of the Differential reinforcement of absence behavior was reached with an average of (2.25) a medium degree.

This may be due to the assessment of teachers of the extent to which these strategies represent good educational 
practice and its importance in behavioral modification. The results of this study are consistent with the importance of strategies with Al-Hiary (2006), which indicated the high importance of most strategies. This indicates the need to focus on these strategies in pre-service and in-service teacher education programs.

As for the gender variable, the results of the study showed that there were no statistically significant differences in the degree of importance of applied behavioral analysis strategies. This result is consistent with the study of Al-Khatib (2005), which showed no significant differences due to sex variable. Orabi (2007) indicated that there were no differences of statistical significance in the level of teachers' knowledge of behavior modification methods for male teachers. The researcher explains this finding that both sexes receive similar training programs before and during the service.

The results of the present study showed that there were statistically significant differences in the mean scores of some strategies such as the strategy of recording the recurrence of behavior, formation and sequencing. These differences were in favor of females. Modeling strategies and punishment were differences in favor of males. (Hiary, 2006) indicated that there were statistically significant differences in the formation strategy for females and the punishment strategy for males.

The results of the study also showed that there were statistically significant differences in the mean scores of some strategies such as strategy of formation, sequence, and activity booster. The differences were in favor of females. This result is partially consistent with Al-Hiari (2006), which indicated the same results. Male symbolic reinforcement is the most commonly used, and social reinforcement in females is the most frequently used among strategies.

In terms of years of experience, the results of the study showed that the level of importance of the strategies of applied behavior analysis for those who have years of experience with autistic children is more than 10 years higher than those who have years of experience with autistic children less than 10 years. This result is an indication that the level of importance of applied behavior analysis strategies is directly proportional to the number of years of experience, and this result is consistent with the study of Hiary (2006), which indicated the same results. The researcher conclude that this may be due to the fact that the most experienced teachers have received many courses and workshops during their careers and have benefited from their colleagues who preceded them in working with children with Autism Spectrum Disorder. Thus, the current study differs with the study (Arabi, 2007) in which the level of knowledge of teachers who had years of experience with autistic children was more than (3) years below the level of knowledge of teachers with years of experience with autistic children less than (3) years. The results of this study also differ with the study of Al-Khatib (2005), Al-Khatib (1993), where these studies indicated that there were no statistical differences due to experience.

As for the variable of educational level, the results of the study showed that there were no statistically significant differences in the mean score of the importance of the applied behavioral analysis strategies due to the level of teacher education. This result was agreed with Al-Khatib (1993), which indicated that there were no significant differences due to the variable qualification. This result explains that the content of the curriculum modification course taught at universities and colleges with limited hours is very similar, which makes them similar at the level. On the other hand, this finding is not consistent with the study of Al-Khatib (2005), Al-Hiari (2006), and Arabi (2007). These studies indicated significant differences in the level of knowledge attributed to the variable of scientific qualification.

The results of the study showed statistically significant differences in the mean score of the importance of behavioral analysis strategies due to the training variable. There were also statistically significant differences in the mean of some strategies such as sequencing, differential reinforcement of opposite behavior and response costs. These differences were in favor of teachers who received training, and this result is consistent with Whaley (2002), Lerman et al. (2004), Cascella and Colella (2004), Grey et al. (2005), AL-Hiary (2006), and Al-Khatib (2005). These studies indicate that the training variable has a significant impact on the level of importance of the strategies of applied behavioral analysis. The researcher believes that private education teachers in general and Autism Spectrum Disorder in particular are in dire need of training, as most special education programs are based on the principles of applied behavior analysis.

Although the results of those studies on the subject of the current study differed and agreed, it is very difficult to generalize these conclusions, since they were based on teachers' responses from their point of view.

\section{Conclusions and Recommendations}

1) The need to focus on applied behavior analysis strategies in the programs of preparing education teachers of colleges and universities. 
2) Since the results of the study were determined according to the self-assessment of special education teachers, the researcher recommends that future studies be concerned to verify the credibility of these results. One possible way to verify the credibility of the results of the study is to use the direct observation card for teachers as they use applied behavioral analysis strategies.

3) Holding training courses for teachers on the applied behavior analysis strategies and its applications.

4) Urge researchers to conduct similar studies to include a larger sample and different geographical areas.

5) Conduct more quantitative and qualitative research on the extent to which teachers know the strategies of applied behavior analysis.

6) Check the effectiveness of programs for autistic children, especially programs based on the principles of applied behavior analysis.

\section{References}

Al-Hiary, G. M. (2006). An investigation of parents and teachers of children with Autism: knowledge levels of importance and use of applied behavioral analysis (Unpublished doctoral dissertation). College of Professional Education, Texas Woman's University.

Al-Khatib, J. (1993). The level of knowledge of teachers of mentally retarded children of behavioral modification methods. Journal of Studies, 20(1), 338-355.

Al-Khatib, J. (2005). The effectiveness of a collective training program in improving the knowledge of teachers of mentally disabled children with behavioral modification skills. Journal of the Union of Arab Universities for Education and Psychology, 3(2), 101-116.

Bogdashina, O. (2006). Theory of mind and the triad of perspective on Autism and Asperger syndrome. London and Philadelphia: Jessica Kingsley Publisher.

Buckendorf, G. R. (2008). Child-Directed, Social-Pragmatic Developmental Approaches. In R. Buckendorf (Ed.), Autism: A guide for educators, clinicians, and parents (pp. 1-16). Thinking Publications, A Division of Super Duper Inc.

Cascella, P. W., \& Colella, C. S. (2004). Knowledge of Autism Spectrum Disorder among Connecticut school speech-language pathologists. Focus on Autism and other Developmental Disabilities, 19(4), $245-252$.

Centers of Diseases Control and Prevention. (2009). Prevalence of Autism Spectrum Disorder. Washington: CDCCP Press.

Charlop, M., \& Haymes, L. (1994). Speech and language acquisition and intervention: Behavioral approaches. In J. L. Matson (Ed.), Autism in children and adults: Etiology, assessment, and intervention (pp. 213-240). Pacific Grove, California: Brooks/ Cole Publishing Company.

Fong, S. F., \& Aldalalah, O. (2010). Effects of Modality and Redundancy Principles on the Learning and Attitude of a Computer-Based Music Theory Lesson among Jordanian Primary Pupils. International Education Studies, 3(3), 52-64. https://doi.org/10.5539/ies.v3n3p52

Granpeesheh, D., Tarbx, J., \& Dixon, D. R. (2009). Applied behavioral analytic intervention for children with Autism Spectrum Disorder-A description and review of treatment research. Annals of Clinical Psychiatry, 21(3), 162-173. Retrieved from https:/www.ncbi.nlm.gov/pubmed/19758537

Grey, I., Honan, R., Mcclean, B., \& Daly, M. (2005). Evaluating the effectiveness of teachers training in applied behavioral analysis principles. Journal of Intellectual Disabilities, 9(3), $209-227$. https://doi.org/10.1177/1744629505056695

Haimour, A. I., \& Obaidat, Y. F. (2013). School Teachers' Knowledge about Autism in Saudi Arabia. World Journal of Education, 3(5), 45-56. https://doi.org/10.5430/wje.v3n5p45

Jaffe, E. (2010). A case study: Use of applied behavior analysis with an autistic adolescent (Doctoral dissertation, Department of Psychology, Philadelphia College of Osteopathic Medicine).

Jarallah, A., Al-Wazzana, T., Al-Ansari, S., \& Hazmi, M. (2006). Autism and similar developmental disorders in Saudi children. Riyadh, Saudi Autism Society.

Lerman, D. C., Vorndran, C. M., Addison, L., \& Kuhn, S. C. (2004). Preparing teachers in evidence- based practice for young children with Autism. School Psychology Review, 33(4), 510-520.

Liedel, J. (2008). Autism: Definition, History, and Diagnosis. In R. Buckendorf (Ed.), Autism, A guide for 
educators, clinicians, and parents (pp. 1-16). Thinking Publications, A Division of Super-Duper Inc.

Orabi, W. (2007). Knowledge of the teachers of autistic children in the Syrian Arab Republic of behavioral modification methods (Unpublished Master Thesis). Faculty of Education, University of Jordan.

Prior, M. (2003). Is there an increase in the prevalence of Autism Spectrum Disorder? Journal of Pediatric Child Health, 39, 78-81. Retrieved from https://www.ncbi.nlm.nih.gov/pubmed/12603792

Scheuermann, B., \& Webber, J. (2002). Autism: Teaching does make a difference. Belmont, CA: Wadsworth/ Thomson Learning.

Shami, W. (2004). Autism Features. Jeddah, Faisaliah Charitable Society for Women.

Smadi, J. (2007). Autism, in Introduction to the Education of Students with Special Needs. Amman, Jordan: Dar Al-Fikr.

Wallin, M. J. (2004). Applied Behavior Analysis. Harbor, Washington, USA.

Whaley, C. H. (2002). Special education teachers and speech therapist knowledge of Autism Spectrum Disorder (Unpublished doctoral dissertation). East Tennessee State University.

\section{Copyrights}

Copyright for this article is retained by the author(s), with first publication rights granted to the journal.

This is an open-access article distributed under the terms and conditions of the Creative Commons Attribution license (http://creativecommons.org/licenses/by/4.0/). 